ISSN: 2641-9475

\title{
Non-Small Cell Lung Cancer Prognosis Based in a Cut-Off Value for Plasma Basic Fibroblast Growth Factor Expression
}

\author{
Laura Nunez-Naveira ${ }^{1,2}$, Carmen Montero-Martinez², and Luis Antonio Marinas-Pardo ${ }^{1,2 *}$ \\ ${ }^{1}$ Biomedical Research Institute of A Coruna (INIBIC), Xubias de Arriba, A Coruna, Spain. \\ ${ }^{2}$ Hospital Universitario A Coruna (CHUAC), Xubias de Arriba, A Coruna, Spain.
}

\section{*Corresponding author:}

\section{Luis Antonio Marinas-Pardo}

University Hospital Complex of A Coruna (CHUAC).

As Xubias de Arriba, 84. PC 15006, A Coruna, Spain.

Received : June 7, 2019

Published : July 30, 2019

\section{ABSTRACT}

Background: Angiogenesis is regulated by angiogenic factors such as vascular endothelial growth factor (VEGF) and basic fibroblast growth factor (bFGF) that may be deregulated in lung cancer. The aim of this study was to find out a pattern of VEGF and bFGF protein expression in exhaled breath condensate $(E B C)$ and serum of non-small cell lung cancer (NSCLC) patients and healthy volunteers (smokers and nonsmokers) to obtain early diagnostic values to discriminate initial stages of disease.

Methods: EBC samples were taken using the EcoScreen device. Protein expression was measured using enzymelinked immunosorbent assays in serum, plasma or EBC from 25 NSCLC patients, 32 healthy smokers and 38 healthy nonsmokers. Youden index was used to determine a cut-off value for each marker.

Results: VEGF expression was higher in NSCLC compared to controls in serum $(p<0.005)$ and EBC $(p<0.05)$ samples. bFGF expression in plasma was also higher in NSCLC $(p<0.05)$. Serum VEGF and plasma bFGF correlated positively ( $R 2=0.4687 ; p<0.05)$. bFGF values over the cut-off were a bad prognosis factor for overall survival in NSCLC patients $(p<0.05)$. Conclusion: VEGF and bFGF expression in blood correlated positively and VEGF could be detected in EBC. The cut-off value for bFGF allowed the identification of patients with higher overall mortality and poor prognosis, independently of age, sex or smoking habit. Considering that bFGF expression seems to be more important in SSC, anti-angiogenic therapy should be selected depending on the histology of the disease.

KEYWORDS: Basic Fibroblast Growth Factor; Biomarker; Exhaled Breath Condensate; Non-Small Cell Lung Cancer; Vascular Endothelial Growth Factor.

stages of disease development [2]. Non-small cell lung cancer (NSCLC) is one of the more important causes of lung cancerrelated death in the Western world in both men and women. Usually when diagnosed, NSCLC has already spread to other poor and the 5-year survival rate decreases with higher 
parts of the body being often hard to treat, the disease is already in a metastatic state, chemotherapy or surgery has a minimal impact on long-term survival and prognosis remains poor for these patients [2]. The early diagnosis of NSCLC is a key factor to significantly improve overall survival in high risk populations of asymptomatic patients [3] but requires the incorporation of novel techniques with high specificity, which are non-invasive, safe, inexpensive and simple to perform.

Changes in the expression of a biomarker are usually related with the susceptibility to have a disease, the risk of progression of the condition or even with the response to a given treatment. Biomarkers may be detected in peripheral blood, urine or tissue. For respiratory diseases, there can also be used bronchoalveolar lavage [4], sputum [5], exhaled gases [6] or exhaled breath condensate (EBC) $[3,7]$. Invasive tests like lung biopsies were the only way to investigate the lungs and lower airways, but breath analysis is promising for biomarker detection.

Tumour angiogenesis pathways have been identified as important therapeutic targets for many cancers, including NSCLC, due to angiogenesis is essential in the process of primary tumour growth, proliferation and metastasis $[8,9]$. Vascular endothelial growth factor (VEGF) seems to have an important role and it has become a major target of antiangiogenic cancer therapy [10]. The literature suggests that the free plasma VEGF concentration is elevated several fold in cancer patients compared to healthy subjects [11]. Besides, the fibroblast growth factor (FGF) family represents a group of heparin-binding, multifunctional polypeptides which also are commonly found dysregulated in malignant tumours [12]. VEGF and FGF have demonstrated co-expression in NSCLC suggesting a synergistic roles in angiogenesis [10]. VEGF initiates the angiogenesis switch, but is not of first importance to the whole process. When the tumours have reached a certain size, other factors such as basic FGF (bFGF), can substitute adequately VEGF. This could explain why in some studies VEGF failed to be a useful marker of long-term survival. Specially in squamous NSCLC, circulating bFGF levels could have a more significant prognostic influence $[13,14]$.

The aim of this prospective study was to find out a pattern of VEGF and bFGF expression in EBC and serum of NSCLC patients and healthy volunteers (smokers and non-smokers) to obtain early diagnostic values that could discriminate initial stages of disease. Ideally, from the data obtained for each biomarker, a cut-off value could be stablished for prognostic purposes.

\section{MATERIALS AND METHODS}

\section{Study site, patients and controls}

The study was approved by the Research Ethics Committee of Galicia (Code 2009/283) and a written informed consent was obtained from all subjects. Participants were recruited from the Pneumology Division at University Hospital Complex of A Coruña, Spain and allocated in experimental or control groups. Experimental group included patients with newly diagnosed NSCLC immediately before histological diagnosis. None of them had received any form of anti-cancer therapy, invasive diagnostic procedure or primary lung surgery. Control group included subjects without lung cancer and no history of chronic obstructive pulmonary disease (COPD) or other respiratory conditions. This group comprised smokers and exsmokers defined as not having smoked for at least 1 year.

\section{Sample collection}

EBC samples were obtained using an EcoScreen condenser (Jaeger, Würzburg, Germany) following current recommendations [15], and rapidly frozen in dry ice. Plasma and serum samples were obtained from peripheral blood. Samples were stored at $-80^{\circ} \mathrm{C}$ for subsequent analysis.

\section{Enzyme linked immunosorbent assay for the determination of biomarkers}

EBC and serum samples were analysed using a sandwich enzyme linked immunosorbent assay (ELISA), Quantikine Human VEGF (R\&D Systems Europe, Abingdon UK). This assay is specific for VEGF and does not detect related molecules such as platelet derived growth factor or placental growth factor. The lower limit of detection for VEGF was $9 \mathrm{pg} / \mathrm{ml}$. bFGF was detected in plasma samples using a specific ELISA kit, Quantikine Human bFGF (R\&D Systems Europe, Abingdon UK). The limit of detection for bFGF was $3 \mathrm{pg} / \mathrm{ml}$. All the assays were performed in duplicate as previously described [16].

\section{Statistical Analysis}

All data were analysed by GraphPad Prism ${ }^{\circledR}$ software Version 5.00 (GraphPad Software, Inc., La Joya, USA) and SPSS 10.0 for Windows (SPSS, Chicago, IL, USA). Box and Whisker plots represent VEGF and FGB values and outliers. The horizontal lines of the boxes represent 25\%, 50\% (median) and 75\% percentiles (from bottom to top). Whiskers represent minimum and maximum values, and circles are outliers. Mann-Whitney test was conducted for the comparison of median values between the lung cancer group and both control groups. 
The inter- relation between determinations was assessed with logistic regression employing Pearson's $R$. Survival rates and curves were calculated by the Kaplan-Meier method and survival curves were compared by log-rank test. For multivariant analysis a Cox's proportional hazards regression model (entry method) was applied to evaluate those variables that were significant predictors of survival. Receiver operating characteristic (ROC) curves and area under the curve (AUC) for ROCs were obtained by plotting sensitivity against the false-positive rate (1-specificity). The Youden index [17] gives the value with the higher score of sensitivity and specificity, it was calculated as Youden=sensitivity + (specificity-1) and used to determine optimal cut-off values for VEGF and bFGF for the identification of the better patients prognosis. Survival differences were assessed by the Log-Rank Test. A p-value lower than 0.05 was considered statistically significant.

\section{RESULTS}

\section{Subjects recruitment}

NSCLC diagnosis was done by bronchoscopy biopsy being squamous cell carcinoma (SSC) $(n=16)$, adenocarcinoma (ADC) $(n=4)$ and other $(n=5)$. NSCLC patients were classified as stage I ( $n=2)$, stage II $(n=5)$, stage III $(n=8)$ and stage IV $(n=10)$. Controls included 32 healthy smokers and 38 healthy nonsmokers (Table 1). Patients underwent EBC and/or wholeblood collection at enrolment. VEGF and bFGF were detected in serum, plasma and EBC samples. VEGF expression was measured in serum and EBC samples. bFGF expression was

measured in plasma samples. VEGF expression was higher in serum compared to EBC in the three groups analysed: cancer, smokers and non-smokers (Table 2). VEGF expression was significantly higher in cancer samples when compared to controls, not only in serum samples (Table 2 and Figure 1A) but also in EBC samples (Table 2 and Figure 1B). Box and Whisker plots identified three outliers in the measures for cancer VEGF EBC, that were not considered for further analysis.

Table 1: Demographic and clinical characteristics of the study subjects.

\begin{tabular}{|c|c|c|c|}
\hline & $\begin{array}{l}\text { Lung Cancer } \\
(n=25)\end{array}$ & $\begin{array}{l}\text { Healthy smokers } \\
(n=32)\end{array}$ & $\begin{array}{l}\text { Healthy non-smokers } \\
(n=38)\end{array}$ \\
\hline Age, years (mean $\pm S D$ ) & $61.04 \pm 11.02$ & $43.24 \pm 9.34$ & $54.84 \pm 7.40$ \\
\hline \multicolumn{4}{|l|}{ Sex, n (\%) } \\
\hline Male & $20(80.00)$ & $21(65.62)$ & $12(35.57)$ \\
\hline Female & $5(20.00)$ & $11(34.38)$ & $26(68.43)$ \\
\hline \multicolumn{4}{|l|}{ Stage, n (\%) } \\
\hline 1 & $2(8.00)$ & - & - \\
\hline II & $5(20.00)$ & - & - \\
\hline III & $8(32.00)$ & - & - \\
\hline IV & $10(40.00)$ & - & - \\
\hline \multicolumn{4}{|l|}{ Histology, n (\%) } \\
\hline ADC & $4(16.00)$ & - & - \\
\hline SCC & $16(64.00)$ & - & - \\
\hline Other & $5(20.00)$ & - & - \\
\hline \multicolumn{4}{|l|}{ Smoking status, n (\%) } \\
\hline Smoker & $16(64.00)$ & $32(100.00)$ & - \\
\hline Ex-smoker & $7(28.00)$ & - & - \\
\hline Non-smoker & $2(8.00)$ & $38(100.00)$ & - \\
\hline
\end{tabular}

Table 2: Comparison of the levels for VEGF in serum and EBC and bFGF in plasma in the three groups of study.

\begin{tabular}{|c|c|c|c|c|c|c|c|c|}
\hline & Group & $\mathbf{N}$ & Median (pg/ml) & Minimum Maximum & Mean Rank & Sum of Ranks & Mann-Whitney U & Asymp. Sig. (2 tailed) \\
\hline \multirow{2}{*}{ VEGF serum } & Cancer & 18 & 244.30 & $79.010-1,446.000$ & 31.500 & 567.00 & \multirow{2}{*}{180.00} & \multirow{2}{*}{0.0288} \\
\hline & Smoker & 32 & 126.50 & $24.590-681.400$ & 22.130 & 708.00 & & \\
\hline \multirow{2}{*}{ VEGF serum } & Cancer & 18 & 244.30 & $79.010-1,446.000$ & 30.390 & 547.00 & \multirow{2}{*}{128.00} & \multirow{2}{*}{0.0046} \\
\hline & Non smoker & 28 & 130.10 & $84.450-463.300$ & 19.070 & 534.00 & & \\
\hline \multirow{2}{*}{ VEGF EBC } & Cancer & 17 & 61.27 & $37.880-329.900$ & 14.590 & 248.00 & \multirow{2}{*}{22.00} & \multirow{2}{*}{0.0154} \\
\hline & Smoker & 7 & 44.75 & $35.210-55.590$ & 7.143 & 50.00 & & \\
\hline \multirow{2}{*}{ VEGF EBC } & Cancer & 17 & 61.27 & $37.880-329.900$ & 14.590 & 248.00 & \multirow{2}{*}{7.00} & \multirow{2}{*}{0.0008} \\
\hline & Non-smoker & 6 & 39.00 & $32.540-41.500$ & 4.667 & 28.00 & & \\
\hline \multirow{3}{*}{ bFGF plasma } & Cancer & 8 & 15.61 & $9.560-65.290$ & 12.000 & 96.00 & \multirow{2}{*}{12.00} & \multirow{2}{*}{0.0190} \\
\hline & Smoker & 9 & 10.55 & $3.267-14.910$ & 6.333 & 57.00 & & \\
\hline & Cancer & 8 & 15.61 & $9.560-65.290$ & 16.250 & 130.00 & \multirow{2}{*}{2.00} & \multirow{2}{*}{$<0.0001$} \\
\hline bFGF plasma & Non-smoker & 12 & 7.49 & $2.288-10.550$ & 6.667 & 80.00 & & \\
\hline
\end{tabular}

Note: VEGF and bFGF units are $\mathrm{pg} / \mathrm{ml}$. Statistical differences were analyzed by Mann-Whitney U test

bFGF, basic fibroblast growth factor; EBC, Exhaled breath condensate; VEGF, vascular endothelial growth factor

bFGF was measured in plasma samples, finding higher values in the cancer group compared to controls (Table 2 and Figure 1C). There was a positive correlation between serum VEGF and plasma bFGF levels (Figure 1D) $\left(R^{2}=0.4687, P<0.05\right)$. High expression of bFGF correlates with poor prognosis in NSCLC.

Citation: Nunez-Naveira L (2019). Non-Small Cell Lung Cancer Prognosis Based in a Cut-Off Value for Plasma Basic Fibroblast Growth Factor Expression. Oncogen 2(4): 17. 
A

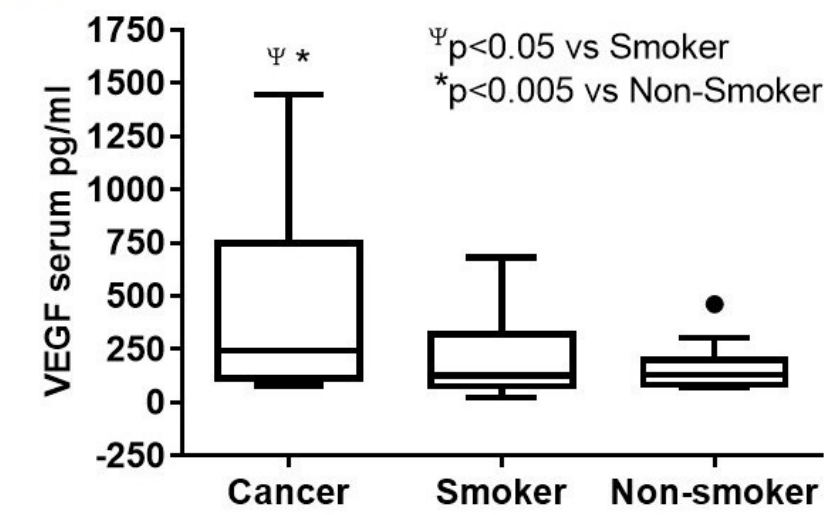

C

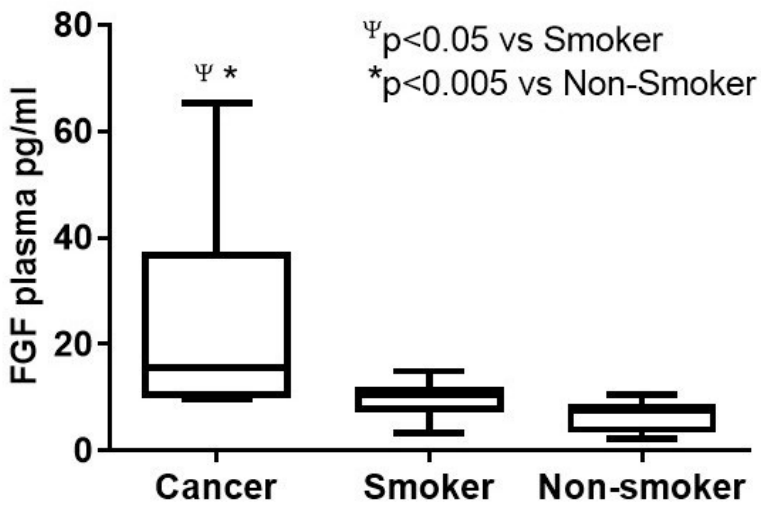

B
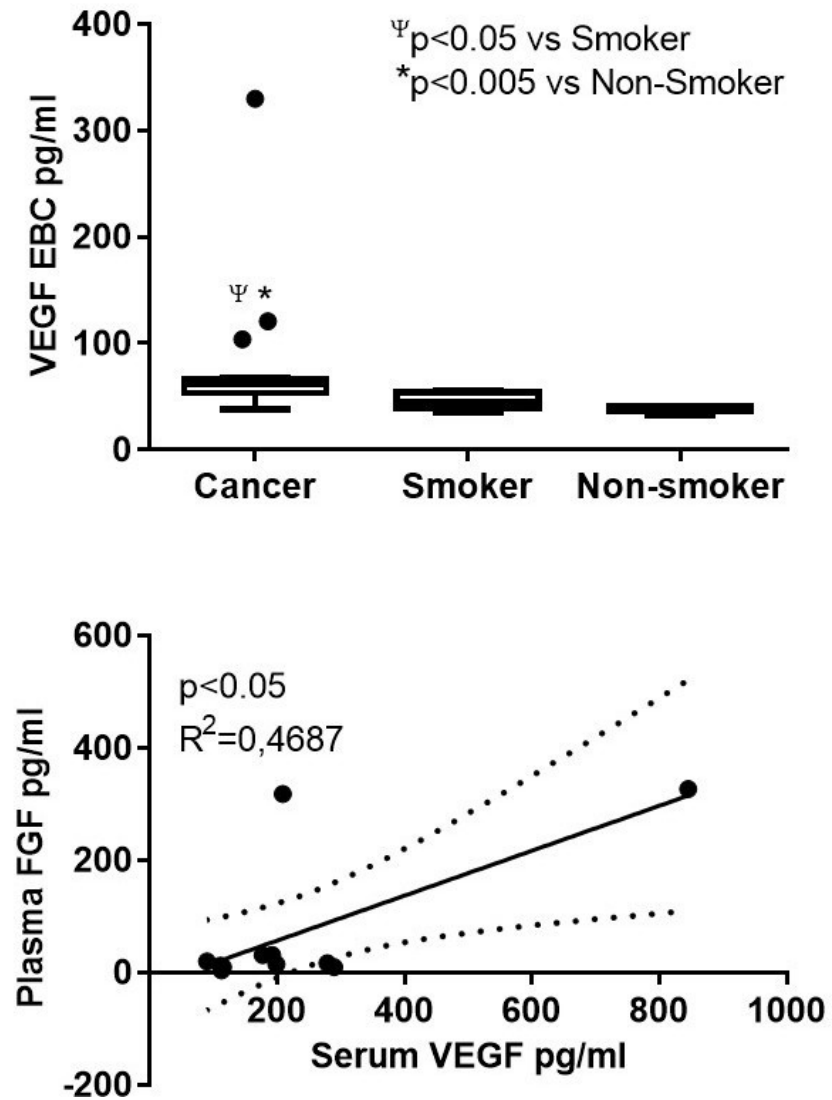

Figure 1: Box and Whisker plots for VEGF and bFGF levels in serum, EBC and plasma (pg/ml) (A) VEGF concentration in serum samples (B) VEGF concentration in EBC samples (C) bFGF concentration in plasma samples (D) Correlation between serum VEGF and plasma bFGF.

The horizontal lines of the boxes represent $25 \%, 50 \%$ (median) and $75 \%$ percentiles (from bottom to top). Whiskers represent minimum and maximum values, and circles are outliers.

Legend: bFGF, basic fibroblast growth factor; EBC, Exhaled breath condensate; VEGF, vascular endothelial growth factor.

A

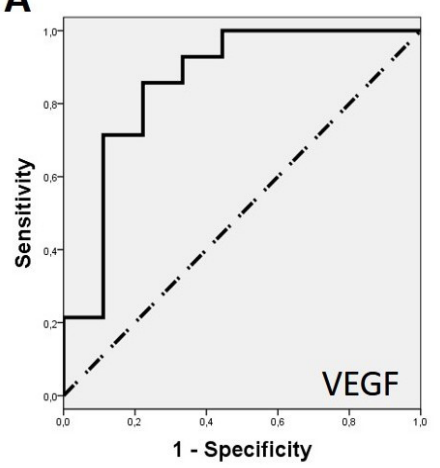

c

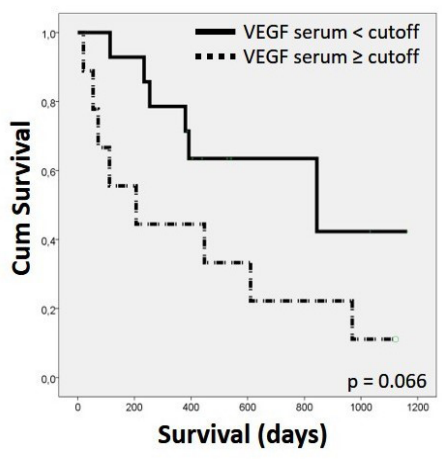

B

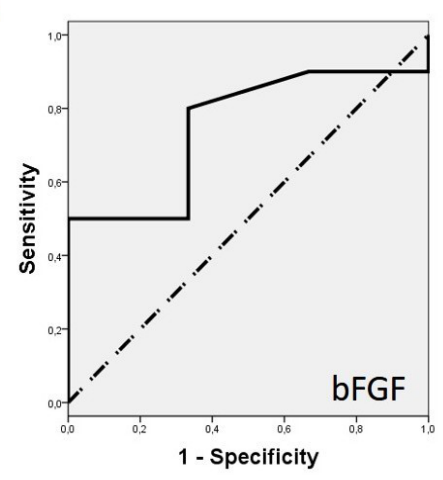

D

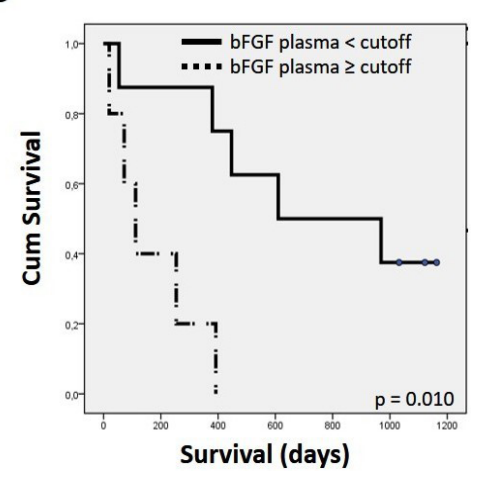

Figure 2: Prognosis value for VEGF and bFGF in serum and EBC samples. (A) ROC curve for serum VEGF (B) ROC curve for plasma bFGF (C) Kaplan-Meier survival curve stratified by serum VEGF cutoff (higher versus lower) (D) Kaplan- Meier survival curve stratified by plasma bFGF cutoff (higher versus lower).

Legend: bFGF, basic fibroblast growth factor; ROC, receiver operating characteristic curve; VEGF, vascular endothelial growth factor. 
A ROC curve was obtained with the values of serum VEGF and plasma bFGF determinations (Figures $\mathbf{2 A}$ and $2 \mathbf{2 B}$ ). The AUC was 0.857 for serum VEGF and 0.750 for plasma bFGF (Table 3). All the results were over 0.75 , the minimum value to consider a ROC curve as a good test. The Youden index was calculated for each marker: $112.209 \mathrm{pg} / \mathrm{ml}$ for serum VEGF and $13.619 \mathrm{pg} / \mathrm{ml}$ for plasma bFGF (Table 3). Serum VEGF expression $\geq 112.209$ $\mathrm{pg} / \mathrm{ml}$ and plasma $\mathrm{bFGF}$ expression $\geq 13.619 \mathrm{pg} / \mathrm{ml}$ were used as indicators for lung cancer global mortality.

Table 3: ROC curve analysis for each marker.

\begin{tabular}{|l|c|c|c|}
\hline & Area under the curve & $\mathbf{9 5 \%} \mathbf{C l}$ & Cut-off \\
\hline Serum VEGF & 0.857 & 0.681 to 1.000 & 112.209 \\
\hline Plasma bFGF & 0.750 & 0.457 to 1.000 & 13.619 \\
\hline $\begin{array}{l}\text { bFGF, basic fibroblast growth factor; } \mathrm{Cl} \text {, confidence interval; ROC, receiver } \\
\text { operating characteristic; VEGF, vascular endothelial growth factor }\end{array}$ \\
\hline
\end{tabular}

Figure 2C shows Kaplan-Meier survival plot generated from curves stratified by serum VEGF levels (higher or lower than the cut-off). Patients' survival was $11.1 \%$ when serum VEGF expression $\geq$ cut-off $(n=9)$ and $57.1 \%$ when < cut-off $(n=14)$. These survival differences were not statistically significant $\left(X^{2}=3.378, P=0.066\right)$. Figure 2D shows the Kaplan-Meier curves stratified by plasma bFGF expression levels. Patients' survival was $0 \%$ when plasma bFGF expression $\geq$ cut-off $(n=4)$ and $37.5 \%$ when<cut-off $(n=8)$. These survival differences were statistically significant $\left(X^{2}=6.549, P=0.010\right)$. Prognostic significance of bFGF as determined by regression analysis. Table 4 shows the result of the multivariate Cox regression model to assess the hazard ratio of bFGF levels in NSCLC patient's survival. The model was considered statistically significant ( -2 Log Likelihood=31.497, $X^{2}=11.289, P=0.024$ ). Plasma bFGF expression, even when controlled for covariates, maintained its prognostic effect in overall survival $(P=0.032)$. The Exp (B) or hazard ratio was 6.837: a NSCLC patient with bFGF expression $\geq$ cut-off value, the odds of dying are 6.837 times larger than the odds for a patient with bFGF expression $<$ cut-off value.

Table 4: Cox regression model to assess the hazard ratio of bFGF levels $\geq$ cut-off in NSCLC patients' survival.

\begin{tabular}{|l|c|c|c|c|c|c|c|}
\hline & B & SE & Wald & df & Sig. & Exp (B) & $\mathbf{9 5 . 0 \%}$ Cl for OR \\
\hline Plasma bFGF & 1.922 & 0.897 & 4.593 & 1 & 0.032 & 6.837 & 1.179 to 39.664 \\
\hline Age & 0.836 & 1.253 & 0.445 & 1 & 0.504 & 2.308 & 0.198 to 26.919 \\
\hline Sex & 1.620 & 1.225 & 1.750 & 1 & 0.186 & 5.053 & 0.458 to 55.709 \\
\hline $\begin{array}{l}\text { Smoking } \\
\text { status }\end{array}$ & -0.619 & 0.898 & 0.476 & 1 & 0.490 & 0.538 & 0.093 to 3.126 \\
\hline
\end{tabular}

$\mathrm{bFGF}$, basic fibroblast growth factor; $\mathrm{Cl}$, confidence interval; $\mathrm{df}$, degrees of freedom; $\operatorname{Exp}(B)$, hazard ratio; SE, standard error; Sig., significance

\section{DISCUSSION}

This study demonstrated a positive correlation between VEGF and bFGF measured in blood from NSCLC patients. Moreover, a cut-off value for bFGF expression could be established and used to differentiate those patients with better prognosis and higher survival rates.

The growth of a tumour beyond a certain size requires angiogenesis to supply the extra input of nutrients, and several growth factors such as VEGF and bFGF participate in this process $[8,9]$. These markers can be detected by immunohistochemistry in lung biopsies [18] or by ELISA in body fluids, mainly blood [19] but also urine [20], bronchoalveolar lavage [21] or pleural effusions [22]. Levels of biomarkers in plasma samples are the reflection of a systemic health situation, but not organ-specific. Blood VEGF varies along the distinct periods of the female life span [23], being more accurate to measure this marker in the $\mathrm{EBC}$ for the study of respiratory diseases $[16,24]$. Nevertheless, some difficulties for EBC analysis have been reported along with some considerations for storage and manipulation of the samples [16]. This study shows that VEGF expression can be detected in EBC and blood, being the concentration higher in serum samples as reported in the literature $[16,25]$. No statistically significant differences could be observed between cancer and control patients. This result might be triggered by the inherent difficulties of processing and conservation of EBC samples with different storage periods [16]. Anyhow, the possibility of detecting biomarkers in EBC makes it a promising sample for lung determinations. VEGF and bFGF levels were found to be higher in NSCLC blood samples compared to healthy subjects, pointing to their possible role in the disease development. A positive correlation between serum VEGF and plasma bFGF was found, suggesting that both markers cooperate during lung disease to promote the necessary angiogenesis for the tumour growth [10]. Considering the above, cut-off values were stablished for VEGF and bFGF and used to obtain survival plots. Clear differences in survival were observed when NSCLC patients were classified according to VEGF or bFGF values higher or lower than the cut-off points. Nevertheless, these differences were only significant for bFGF.

The most common histologic subtype of NSCLC is adenocarcinoma (40\%), followed by SCC (25\% to 30\%), and large cell carcinomas (5\% to 10\%) [26]. NSCLC anti- angiogenic therapies are mainly aimed at patients with adenocarcinomas, where VEGF seems to perform a crucial role [27]. Bevacizumab is a recombinant humanized monoclonal antibody that 
neutralizes VEGF activity by blocking its binding with VEGF receptor, and it is the only approved antiangiogenic agent for patients with NSCLC [28]. There are several drugs that inhibit the angiogenesis by blocking different pathways in combination with chemotherapy [29], but only approximately $50 \%$ of subjects respond to the treatment. It seems that due to the redundancy in the angiogenesis signalling not only VEGF but also other factors might have a role in the development of resistance to angiogenic treatments [30].

SCC has showed heterogeneity in angiogenic and proliferative behaviour, highlighting the need for new therapies alternative to VEGF inhibitors [27]. Dysregulation of the FGF receptor (FGFR) pathway has been observed in NSCLC particularly in patients with SCC. There is accumulating evidence that points toward a role for inhibiting the angiogenic FGF/FGFR signalling pathway in SCC $[13,14,31]$, the majority of patients included in this study (64.00\%), which could have biased the interpretations and it is in accordance with the observed results for VEGF and bFGF.

bFGF cut-off value could identify patients with higher risk of mortality, thus pointing to the specific role of bFGF in NSCLC development. It might be used for NSCLC prognosis even when controlled by age or sex, and also independently of the smoking status. Anyhow, given the higher percentage of SCC patients in the analysed group, these interpretations might be better applied to this specific cancer type. According to the results, these patients should be treated with drugs based on the inhibition of bFGF rather than VEGF, although these results should be tested in a larger group to assure the interpretation. NSCLC type might be a point to consider when selecting the therapy with angiogenesis inhibitors.

The global burden of lung cancer increases due to the aging of the population alongside an increasing adoption of cancercausing behaviours such as smoking. Lung cancer is the worldwide leading cause of cancer death among males and females [32]. In this study, age, sex or smoking status did not have impact in mortality when analysed with the bFGF cutoff value. Although most studies suggest that overall survival is better in non-smokers [33], it was shown that the smoking status at the time of lung cancer diagnosis has poor impact on the long- term survival of patients with NSCLC [34].

Besides, active smoking was not found as a prognosis factor in men [35]. Previous publications found that smokers had a higher survival rate compared to non-smokers in NSCLC [36] but also that the impact of smoking status was only important when the status disease was diagnosed in an early stage [37]. Lung cancer in non-smokers is often diagnosed at a late stage, being first attributed to a respiratory infection or even allergies.

Considering that the majority of individuals included in our study were diagnosed of NSCLC in later stages $(n=18)$ versus early stages ( $n=7)$, the lack of effect of smoking status might be a biased interpretation. This study has some limitations related to the small sample size that could be biasing the results due to the unproportioned subgroups of NSCLC type. Besides, due to volume sample limitation, bFGF could not be determined in EBC samples so new patient recruitment would be necessary to confirm if the results observed in plasma are replicable in this sample.

\section{CONCLUSION}

This study demonstrates a positive correlation between angiogenesis biomarkers (VEGF and bFGF) in blood and also that VEGF could be detected in EBC. A cut-off value for bFGF could be stablished to identify patients with higher overall mortality and poor prognosis, independently of age, sex or smoking habit. Finally, bFGF expression seems to be more important in SSC, suggesting that anti-angiogenic therapy should be selected depending on the histology of the disease.

\section{CONFLICT OF INTEREST}

The authors report no conflicts of interest.

\section{FUNDING}

This work was supported by the Sociedad Española de Neumología y Cirugía Torácica (Separ); and the Instituto de Salud Carlos III [grant number FIS 06/1643].

\section{REFERENCES}

1. Eurostat. Statistics Explained: Cancer statistics - specific cancers. Eur. Union. 2017 [Internet]. https://ec.europa.eu/ eurostat/statistics-explained/index.php?title=Cancer_ statistics_-_specific_cancers June 7, 2018 date last accessed.

2. Goldstraw P, Chansky K, Crowley J, Rami-Porta R, Asamura H, Eberhardt WE, et al. (2016) The IASLC Lung Cancer Staging Project: Proposals for Revision of the TNM Stage Groupings in the Forthcoming (Eighth) Edition of the TNM Classification for Lung Cancer. J Thorac Oncol 11(1): 39-51.

3. Gasparri R, Romano R, Sedda G, Borri A, Petrella F, Galetta 
D, et al. (2018) Diagnostic biomarkers for lung cancer prevention. J Breath Res 12(2): 027111.

4. Charpidou A, Gkiozos I, Konstantinou M, Eleftheraki A, Demertzis P, Harrington K, et al. (2011) Bronchial washing levels of vascular endothelial growth factor receptor-2 (VEGFR2) correlate with overall survival in NSCLC patients. Cancer Lett 304(2): 144-153.

5. Bourdin A, Kotsimbos T, Nguyen K, Vachier I, Mainprice $B$, Farce $M$, et al. (2010) Non-invasive assessment of small airway remodelling in smokers. COPD 7(2): 102-110.

6. Grob NM, Dweik RA (2008) Exhaled nitric oxide in asthma: Progress since the introduction of standardized methodology. J Breath Res 2(3): 37002.

7. Barta I, Kullmann T, Csiszer E, Antus B (2010) Analysis of cytokine pattern in exhaled breath condensate of patients with squamous cell lung carcinoma. Int J Biol Markers 25(1): 52-56.

8. Mantovani A (2009) Cancer: Inflaming metastasis. Nature 457(7225): 36-37.

9. Hanahan D, Weinberg RA (2000) The hallmarks of cancer. Cell 100(1): 57-70.

10. Piperdi B, Merla A, Perez-Soler R (2014) Targeting Angiogenesis in squamous non-small cell lung cancer. Drugs 74(4): 403-413.

11. Kut C, Mac Gabhann F, Popel AS (2007) Where is VEGF in the body? A meta- analysis of VEGF distribution in cancer. Br J Cancer 97(7): 978-985.

12. Tanner Y, Grose RP (2016) Dysregulated FGF signalling in neoplastic disorders. Semin Cell Dev Biol, 53: 126-35.

13. Hu M, Hu Y, He J, Li B (2016) Prognostic Value of Basic Fibroblast Growth Factor (bFGF) in lung cancer: A systematic review with meta-analysis. PLoS One 11(1): e0147374.

14. Hu MM, Hu Y, Gao GK, Han Y, Shi GL, Li BL (2015) Basic fibroblast growth factor shows prognostic impact on survival in operable non-small cell lung cancer patients. Thorac Cancer 6(4): 450-457.

15. Horvath I, Hunt J, Barnes PJ, Alving K, Antczak A, Baraldi E, et al. (2005) Exhaled breath condensate: Methodological recommendations and unresolved questions. Eur Respir J
26(3): 523-548.

16. Nunez-Naveira L, Marinas-Pardo LA, Amor-Carro O, Montero-Martinez C (2012) Determination of ELISA reproducibility to detect protein markers in exhaled breath condensate. J Breath Res 6(4): 046003.

17. Klotsche J, Ferger D, Pieper L, Rehm J, Wittchen HU (2009) A novel nonparametric approach for estimating cut-offs in continuous risk indicators with application to diabetes epidemiology. BMC Med Res Methodol 9: 63.

18. Pajares MJ, Agorreta J, Larrayoz M, Vesin A, Ezponda T, Zudaire l, et al. (2012) Expression of tumor-derived vascular endothelial growth factor and its receptors is associated with outcome in early squamous cell carcinoma of the lung. J Clin Oncol 30(10): 1129-1136.

19. Matsuyama W, Hashiguchi T, Mizoguchi A, Iwami F, Kawabata M, Arimura K, et al. (2000) Serum levels of vascular endothelial growth factor dependent on the stage progression of lung cancer. Chest 118(4): 948-951.

20. Bok RA, Halabi S, Fei DT, Rodriquez CR, Hayes DF, Vogelzang NJ, et al. (2001) Vascular endothelial growth factor and basic fibroblast growth factor urine levels as predictors of outcome in hormone-refractory prostate cancer patients: A cancer and leukemia group B study. Cancer Res 61(6): 2533-2536.

21. Crohns $M$, Saarelainen $S$, Laine $S$, Poussa $T$, Alho $\mathrm{H}$, Kellokumpu-Lehtinen P (2010) Cytokines in bronchoalveolar lavage fluid and serum of lung cancer patients during radiotherapy: Association of interleukin-8 and VEGF with survival. Cytokine 50(1): 30-36.

22. Sack U, Hoffmann M, Zhao XJ, Chan KS, Hui DS, Gosse H, et al. (2005) Vascular endothelial growth factor in pleural effusions of different origin. Eur Respir J, 25(4): 600-604.

23. Malamitsi-Puchner A, Tziotis J, Tsonou A, Protonotariou E, Sarandakou A (2000) Basic fibroblast growth factor: serum levels in the female. Growth Factors 17(3): 215-220.

24. Dalaveris E, Kerenidi T, Katsabeki-Katsafli A, Kiropoulos T, Tanou K, Gourgoulianis KI, et al. (2009) VEGF, TNF-alpha and 8-isoprostane levels in exhaled breath condensate and serum of patients with lung cancer. Lung Cancer 64(2): 219-225.

25. Hoffmann HJ, Tabaksblat LM, Enghild JJ, Dahl R (2008) 
Human skin keratins are the major proteins in exhaled breath condensate. Eur Respir J 31(2): 380-384.

26. Zappa C, Mousa SA (2016) Non-small cell lung cancer: current treatment and future advances. Transl Lung Cancer Res 5(3): 288-300.

27. Salgia R (2014) Fibroblast growth factor signaling and inhibition in non-small cell lung cancer and their role in squamous cell tumors. Cancer Med 3(3): 681-692.

28. Russo AE, Priolo D, Antonelli G, Libra M, Mccubrey JA, Ferrau $F$ (2017) Bevacizumab in the treatment of NSCLC: patient selection and perspectives. Lung Cancer (Auckl) 8: 259-269.

29. Malhotra J, Jabbour SK, Aisner J (2017) Current state of immunotherapy for non-small cell lung cancer. Transl Lung Cancer Res 6(2): 196-211.

30. Erber R, Thurnher A, Katsen AD, Groth $G$, Kerger $H$, et al. (2004) Combined inhibition of VEGF and PDGF signaling enforces tumor vessel regression by interfering with pericyte-mediated endothelial cell survival mechanisms. FASEB J 18(2): 338-340.

31. Naumnik W, Ossolinska M, Płońska I, Chyczewska E, Nikliński J (2014) Circulating thrombospondin-2 and FGF2 in patients with advanced non- small cell lung cancer: Correlation with survival. Adv Exp Med Biol 833: 9-14.
32. Torre LA, Bray F, Siegel RL, Ferlay J, Lortet-Tieulent J, Jemal A (2015) Global cancer statistics, 2012. CA Cancer J Clin 65(2): 87-108.

33. Rudin CM, Avila-Tang E, Harris CC, Herman JG, Hirsch FR, Pao W, et al. (2009) Lung cancer in never smokers: molecular profiles and therapeutic implications. Clin Cancer Res 15(18): 5646-5661.

34. Meguid RA, Hooker CM, Harris J, Xu L, Westra WH, Sherwood JT, et al. (2010) Long-term survival outcomes by smoking status in surgical and nonsurgical patients with non-small cell lung cancer: Comparing never smokers and current smokers. Chest 138(3): 500-509.

35. Debieuvre D, Oster J-P, Riou R, Berruchon J, Levy A, Mathieu JP, et al. (2016) The new face of non-small-cell lung cancer in men: Results of two French prospective epidemiological studies conducted 10 years apart. Lung Cancer 91: 1-6.

36. Kim JH, Kim HS, Kim BJ (2017) Prognostic value of smoking status in non-small-cell lung cancer patients treated with immune checkpoint inhibitors: A meta- analysis. Oncotarget 8(54): 93149-93155.

37. Fox JL, Rosenzweig KE, Ostroff JS (2004) The effect of smoking status on survival following radiation therapy for non-small cell lung cancer. Lung Cancer 44(3): 287-293.

Copyright: Nunez-Naveira L, et al. @2019. This is an open-access article distributed under the terms of the Creative Commons Attribution License, which permits unrestricted use, distribution, and reproduction in any medium, provided the original author and source are credited. 